\title{
Report to the A.L.A. Bibliography Committee on the Assembly of Librarians of the Americas
}

\section{Miss Beetle is head, Foreign Language} Section, Descriptive Cataloging Division, Library of Congress.

$\mathrm{T}$

HE Assembly of Librarians of the Americas met in Washington, D.C., May I3-June 7, 1947. It was attended by more than thirty delegates from Latin American countries and from Canada and the Philippines. At the inaugural session, they were welcomed by the Librarian of Congress and by representatives of the State Department, the American Library Association, and the Pan American Union. Many United States librarians were present at this and later meetings and participated in preparations and discussions.

The objectives of the assembly were to foster library development in the Americas and to stimulate library relations among the countries of the Americas. At the second general session, papers were presented which urged that in the organization of Latin American libraries a happy medium be kept between the two conflicting philosophies of librarianship: the European, in which technical advance is retarded, and the American, in which technique is sometimes over-emphasized.

The assembly was planned as a combination conference and workshop. For the latter function, five committees were organized :

I. Education for librarianship

II. Technical processes
III. Acquisitions

IV. Bibliography

V. Library services and development

The Bibliography Committee consisted of twenty-six members, with Miron Burgin and Augusto Raúl Cortázar serving as cochairmen. The purpose was to study the possibilities of ( $\mathrm{I}$ ) compiling a bibliography of current Latin American bibliographies of national character; (2) establishing standards for compiling national bibliographies; (3) preparing a pamphlet on the principal bibliographies published throughout the world with information concerning purchase; (4) compiling a trade bibliography for Latin America; (5) compiling standard buying guides; (6) compiling lists of translations or suggestions for translations; (7) publishing library journals in Spanish, Portuguese, and French in the field of library literature; (8) a complete bibliography of library literature published in Spanish, Portuguese, and French; and (9) a selective bibliography in all languages on library science.

After the organizing meeting, at which Fermín Peraza was elected secretary, the committee was divided into two subcommittees, the first to consider points $I-6$, of the topics of discussion, with special attention to the compilation of a bibliography of current Latin American bibliographies of national character; the second to consider points $7-9$, that is, the topics relating to 
library literature.

The assembly adopted the following resolutions presented by the Committee on Bibliography :

National Bibliographies. In view of the circumstance that repeated recommendations of international organizations concerning the desirability of publishing national bibliographies have not been heeded except in a few countries, the Assembly of Librarians of the Americas resolves to recommend that national libraries or bibliographical institutions be charged with the duty of bringing to fruition the compilation and publication of national bibliographies of their respective countries, where such work is not already being realized either commercially or by government agencies.

Bibliography of National Bibliographies. The Assembly of Librarians of the Americas resolves to recommend urgently the compilation of bibliographies of national bibliographies as the starting point of continued progress in this field.

On the basis of past experience it recommends to the Library of Congress that it continue its praiseworthy program of inviting consultants for the purpose of compiling such bibliographies, through revision and expansion of compilations previously prepared in the respective country.

To recommend also that insofar as possible the Library of Congress publish such bibliographies in its Latin American series.

Bibliography of Library Science. The Assembly of Librarians of the Americas resolves:

I. To approve compilation of a Latin American bibliography on library science in accordance with the following specifications:

a. The bibliography is to comprise books, pamphlets, and writings of Latin American authors on library science, whatever the topic, as well as works on Latin American library science by any author and in any language.

b. The bibliography is to include: book science, library administration, bibliography on library science and techniques.

c. The bibliography is to include works published beginning Jan. I, 1948.

d. Entries may be annotated, provided that the notes be limited to forty words. e. Other characteristics of the bibliography will be determined by the Latin American Commission on Library Science Bibliography at the suggestion of the secretary general.

2. To constitute for this purpose a Latin American Commission on Library Science Bibliography composed of at least one representative from each country as follows: Argentina, Augusto Raúl Cortázar and Ernesto Gietz; Bolivia, Adrián Camacho Porcel; Brazil, Rubens Borba de Moraes, Maria Louisa Monteiro, and Bernadette Sidnay Neves; Chile, Héctor Fuenzalida; Colombia, Rubén Pérez Ortiz; Costa Rica, Julián Marchena; Cuba, Fermin Peraza; Dominican Republic, Emilio Rodríguez Demorizi; Ecuador, Alfredo Chaves; El Salvador, Baudilio Torres; Guatemala, Ricardo Casteñeda Paganini; Haiti, Raymond Lavelanet; Mexico, Rafeel García Granados; Nicaragua, Gaston Litton; Panama, Galileo Patiño; Paraguay, Abdón Alvarez; Peru, Jorge Basadre; Uruguay, Arthur E. Gropp; Venezuela, Enrique Planchart; Puerto Rico, Gonzalo Velázquez; Philippines, Gabriel A. Bernardo.

3. To make each member of the commission responsible for the compilation of the bibliography for his country and for delivery on time of the compilation to the secretariat.

4. To designate the Institute of Library Science, University of Buenos Aires, as the secretariat general, and Dr. Augusto Raúl Cortázar, director, Library of the Department of Philosophy and Letters, University of Buenos Aires, as secretary general. Dr. Cortázar will be in charge of all activities relating to the assembly, coordination and publication of the materials, and will present to the commission whatever problems he may encounter in performing this task.

Retrospective Bibliography in Library Science. The Assembly of Librarians of the Americas resolves to recommend that the Latin American Commission on Bibliography of Library Science study the problem of organizing a retrospective bibliography of library science relating to Latin America, and that the secretary general report on this subject to the next assembly of librarians. This study should not interfere with such preliminary work as may be undertaken in each of the constituent countries, with a view toward the publication of such materials in accord- 
ance with norms established for the current bibliography on library science.

Subject Headings. The Assembly of Librarians of the Americas resolves to thank H. W. Wilson for granting permission to the Latin American Commission on Bibliography of Library Science to use and translate into Spanish the Subject Headings on Library Literature, and to express its satisfaction to the Institute on Library Science of the University of Buenos Aires for its offer to translate the Subject Headings on Library Science and to distribute the list to members of the commission prior to Jan. I, 1948.

Special Bibliographies. The Assembly of Librarians of the Americas resolves to recommend that the countries of the Americas encourage bibliographic activities in specialized fields and that for this purpose national, provincial, and municipal prizes be established for the best studies; to recommend also that cultural institutions which have already established competitions add prizes to cover specifically bibliographical works; to recommend that universities encourage bibliographical research by establishing a minimum requirement for such research in the various departments, and that such studies be preserved; and to recommend to the Pan American Union that it study the possibility of encouraging bibliographical research in special fields and that it facilitate publication of such works.

Bibliographies of Special Bibliographies. The Assembly of Librarians of the Americas calls attention to the increasing complexity of bibliographic control in specialized fields of knowledge and recommends that UNESCO give careful and sympathetic consideration to the problem of compiling a bibliography of specialized bibliographies currently published throughout the world.

Bibliographies of Translations. The Assembly of Librarians of the Americas welcomes with profound satisfaction the efforts hitherto made in the field of translations of United States books into Spanish, Portuguese, and French. Convinced that these activities not only contribute significantly to the cultural unity of the Americas, but that they also provide considerable assistance in the urgent task of promoting more successfully the material welfare of the Latin American republics, the assembly hopes that these pro- grams of the Department of State as well as of publishers throughout the Americas will be continued with undiminished vigor.

In order to insure in Latin America the greatest possible utilization of the intellectual resources created by such efforts the assembly suggests that the United States Department of State give special consideration to the establishment in the Library of Congress of a central office for the compilation and dissemination of bibliographical information concerning translations of United States works into Spanish, Portuguese, and French. Such bibliographical lists should cover publications already translated as well as works to be translated. It is suggested that the proposed compilation cover not only current translations but also a retrospective bibliography of United States works translated into Spanish, Portuguese, and French.

The Assembly of Librarians of the Americas strongly recommends that publishing houses, bibliographical centers, and national libraries in Latin America cooperate to the fullest possible extent in the realization of this program by placing at the disposal of the proposed office all the relevant information in their hands. For this purpose delegates present at this assembly are urged to render all possible assistance, either individually or through especially organized commissions.

Bibliography of Periodicals. The Assembly of Librarians of the Americas resolves to recommend that the $\mathrm{P}$ an American Union establish in the Pan American Book Shelf a special section for the listing of new Latin American periodicals and that for this purpose the Pan American Union request assistance of all the relevant agencies and institutions, such as national bibliographical commissions, copyright offices, post offices, etc.

Bibliography of Articles in Periodicals. The Assembly of Librarians of the Americas resolves to thank $\mathrm{H}$. W. Wilson for his offer to include in his Readers' Guide to Periodical Literature articles appearing in the principal Latin American reviews, and to offer to $\mathrm{Mr}$. Wilson the collaboration of librarians present at the assembly for the purpose of selecting the periodicals.

Minimum Bibliographical Standard. The Assembly of Librarians of the Americas resolves to recommend that in reviews of bibliographical nature published in newspapers and 
periodicals the following information be given: author, title, edition, translator, place of publication, publisher or printer, date, number of pages or volumes, illustrations, series, and price; to recommend that in all bibliographical compilations entries should be as complete as possible in accordance with cataloging rules, and that at least the minimum standards defined above be observed; and to recommend that the secretariat of the assembly and the delegates give the widest possible publicity to this resolution.

Selective Bibliographies. The Assembly of Librarians of the Americas resolves to express satisfaction of the kind of work performed by Elvira Renée Rodriguez, graduate of the Library School of the Asociacion de Ingenieros, of Montevideo, in preparing a Selective Bibliography of 500 Works Representative of Uruguayan Culture, and to recommend that similar selected bibliographies be prepared in other countries, as a practical method of disseminating information concerning the cultural attainments of the country.

A seminar on "Union Catalogs and $\mathrm{Li}$ brary Resources" was held on May 23, 1947. Following an address by M. Julien Cain, director, Bibliothèque Nationale, the discussion on union catalogs was opened by Paul Vanderbilt, who mentioned two schools of thought; one, the group that is satisfied with solving the location problem by means of union catalogs; two, the group that is concerned with the relation of union catalogs to the more complex picture of identification of items, acquisitions development, and cataloging and recataloging.

Miss Franco mentioned a union catalog of periodicals which has been established at São Paulo. Dr. Fuenzalida mentioned a union catalog at the University of Chile, consisting of Library of Congress printed cards for books by Latin American authors and books about Latin America by authors from all countries and in all languages, against which other catalogs are being checked for additions.
Dr. Peraza, of Cuba, suggested that it was extremely desirable that a uniform code of cataloging and classification be used in the Americas, in order to simplify the work of compiling a union catalog. Both Dr. Peraza and Sr. Penna, of Argentina, advocated considering some modifications of the A.L.A. rules in order to make them more international in certain cases.

Dr. Planchart, of Venezuela, mentioned that copies of the catalog cards of the $\mathrm{Na}$ tional Library of Caracas had, since I938, been sent to the Union Catalog of the Library of Congress. He mentioned also a union catalog of medical books available in Venezuela, prepared in printed form by the Instituto Bibliotecológico of Caracas.

At the final session of the Assembly on June 7, 1947, an executive committee of five members, Jorge Basadre, Ernesto Gietz, Fermín Peraza, Rubens Borba de Moraes, and Luther H. Evans, was constituted to prepare plans for a second assembly to be held probably in 1949 at a place to be determined later. Thus the cooperative effort of the first assembly, with its constructive and progressive spirit so apparent, may be considered to have accomplished its purpose.

The plans and hopes of the delegates to the assembly indicate their energy and vision. Too often they may be prevented from carrying these plans into effect because of lack of funds. H. W. Wilson has offered help by including Latin American material in his publications, the Readers' Guide to Periodical Literature and the bibliography of Library Literature, which has resumed publication after being suspended during the war years. Any concrete assistance which can be given by the A.L.A. Bibliography Committee will certainly be appreciated and should be profitable to North American as well as to Latin American librarians. 